\title{
ANÁLISE DO CONTROLE DA LIVRE CONCORRÊNCIA PARA DEFESA DO CONSUMIDOR
}

\author{
Larissa Peixoto Valente ${ }^{1}$
}

\section{RESUMO}

O objetivo deste trabalho é analisar brevemente como a proteção da livre concorrência reflete na promoção dos direitos do consumidor no Estado dualista, como é o caso do brasileiro. As considerações se iniciam diante da conceituação da ordem econômica, identificação dos melindres do Direito Econômico e a concepção de Constituição Econômica, os princípios que a compõem de modo integrativo como a liberdade de iniciativa, liberdade de concorrência e a defesa do consumidor. Diante de tais conceitos, averigua-se a possibilidade do controle do mercado mediante instrumentos normativos infraconstitucionais e órgãos da administração pública indireta para promover a liberdade de concorrência com o controle da liberdade de iniciativa, bem como o favorecimento da defesa do consumidor.

Palavras-chaves: Defesa do Consumidor; Estado Dualista; Intervenção estatal; Livre Concorrência; Ordem Econômica.

\section{ANALYSIS OF THE CONTROL OF FREE COMPETITION TO CONSUMER DEFENSE}

\begin{abstract}
The objective of this work is to analyze briefly how the protection of free competition reflects in the promotion of consumer rights in the dualistic State, as is the case of the Brazilian. The considerations begin with the conceptualization of the economic order, identification of the misdeeds of Economic Law and the conception of economic constitution, the principles that compose it as freedom of initiative, freedom of competition and consumer protection. Faced with such concepts, the possibility of controlling the market through regulatory instruments and public agencies of the indirect administration is investigated to promote the freedom of competition with the control of freedom of initiative, as well as the favoring of consumer protection.
\end{abstract}

Keywords: Consumer defense; Dualist State; State intervention; Free competition; Economic Order

\section{INTRODUÇÃO}

O tema sobre o controle da concorrência para garantir a estabilidade da livre concorrência para defesa dos direitos do consumidor permite identificar o dever de Estado intervir, fiscalizando a atividade empresarial ou incentivando-a. Apresenta-se como inovadora

\footnotetext{
${ }^{1}$ Doutoranda em Direito na Universidade Federal da Bahia (UFBA). Mestre em Direito Público pela Universidade Federal da Bahia (UFBA) e Bacharel pela Universidade Federal da Bahia (UFBA).
} 
a perspectiva de investigar como a proteção da livre concorrência por parte do Estado mediante a fiscalização e controle de abuso do poder econômico pode proteger os direitos do consumidor. Ademais, justifica-se essa intervenção pelo próprio fato de o Estado brasileiro ser dualista: ao mesmo tempo que assume uma posição de incentivo e respeito à livre iniciativa, deve efetivar os direitos sociais atinentes a proteção dos vulneráveis na relação consumerista.

Diante de tais considerações, observa-se a importância de se adentrar na pesquisa sobre o conteúdo temático da ordem econômica sobre a qual o Estado irá intervir para promovê-la. A característica que lhe é peculiar, dualista, permite que sejam instituídas leis inibidoras ou incentivadoras de comportamentos da livre iniciativa para promover os direitos sociais. No entanto, pode parecer uma incógnita como referida ação estatal se apresenta para efetivamente conservar e proteger os direitos dos consumeristas. Isto porque se observam poucas leis esparsas e órgãos que foram criados para controlar e evitar o abuso econômico por parte da livre iniciativa prejudicial aos consumidores. Aí está, inclusive, a sua relevância, afinal o presente artigo busca justificar o controle do mercado como defesa dos direitos do consumidor pelos próprios instrumentos de que dispõe o Estado: atuação de incentivo ou proibição e fiscalização.

Para fins de compreensão da temática abordada, tem-se como objetivos: identificar, primeiramente, a ordem econômica e a parte do ordenamento jurídico brasileiro que dela trata, bem como a relação entre estes dois elementos; descreverem-se as características do Estado dualista para justificar a possibilidade de intervenção sobre a livre iniciativa, promovendo tanto a atividade econômica, assim como a defesa dos direitos sociais, como é o caso do direito dos consumidores. Para realizar tal intervenção, encontram-se os instrumentos normativos, os serviços públicos e as agências reguladoras e os órgãos de controle da concorrência para evitar o abuso econômico e a concentração empresarial com o fim de defender a própria atividade econômica e os direitos dos consumidores.

Para a realização e desenvolvimento da pesquisa para elaboração deste trabalho adotou-se como método de abordagem o hipotético dedutivo com uma pesquisa qualitativa, dedutiva e descritiva, utilizando como elementos de pesquisa artigos doutrinários, enxertos de livros e diplomas legais.

\section{ORDEM ECONÔMICA, DIREITO ECONÔMICO E CONSTITUIÇÃO ECONÔMICA}


O Estado pode atuar no domínio econômico de diversas formas, operando como um agente participativo ou como agente normativo fiscalizador ou incentivador. No entanto, somente no domínio econômico, como prediz o artigo 174 da Constituição Federal de 1988.

Sobre o domínio econômico, são diversas as acepções que se destinam a conceituálo. Em sentido amplo, tem-se como conjunto de atividades econômicas, realizadas pela administração pública ou ente privado, sendo estas ligadas à produção e distribuição de bens e prestação de serviços de mercado (COMPARATO, 1999, p 256). Num sentido mais estrito, basta retirar desse conjunto de atividades os que são considerados serviços públicos, que são os prestados pelo Estado, em regime de direito público (GRAU, 2015, p 141).

O conceito de domínio econômico se identifica como descrição de relações sociais, relacionadas diretamente com as atividades de produção, circulação de bens e prestação de serviços para o mercado (GAMA, 2013, p 230). Esse conceito pode ser destrinchado de forma a identificar que a expressão domínio econômico está fora do sistema de direito positivo, posto que é linguagem descritiva, que relata as atividades desenvolvidas fora do sistema jurídico, no âmbito do mercado, ou seja, num espaço em que os consumidores possuem liberdade para decidir sobre aquilo que deve ser produzido, abstraídas as técnicas de condução das preferências deles (BRITO, 2016, p 43). Quanto ao fato de se referir à produção e circulação de bens e prestação de serviços para o mercado, observa-se que os fatos sociais desenvolvidos no domínio econômico são diversos dos demais fatos sociais de natureza não econômica (GAMA, 2013, p 231), consubstancializando-se, em verdade, em atividades que representam um campo específico e exclusivo da iniciativa econômica popular (VENANCIO FILHO, 1998, passim).

Em relação à ordem econômica, deve-se entender como um conjunto de normas jurídicas que disciplinam as relações econômicas. Em outras palavras, é o conjunto de normas dirigidas à regulação das atividades desenvolvidas no domínio econômico, que formam o Direito Econômico. A ordem econômica é, portanto, o plexo normativo, de natureza constitucional, no qual são fixadas a opção por um modelo econômico e a forma como deve se operar a intervenção do Estado no domínio econômico (SILVA NETO, 2001, p 134).

O Direito Econômico é uma das divisões do direito social, definindo-se como o conjunto de princípios e normas que disciplinam a atividade do Estado e dos demais sujeito da ordem jurídica, quando equacionada à consecução dos objetivos econômicos da coletividade (MAGANO, [s.d.]). Os autores brasileiros consideram que o Direito Econômico possui três esferas: Direito Administrativo Econômico, Direito do Planejamento e o Direito da Organização dos Mercados. Tais disciplinas se fundam na ideologia do desenvolvimento e do 
bem-estar social. A última vertente se revela na perspectiva de o Direito Econômico ser um conjunto de normas que visa reintroduzir os elementos de mercados, como lucro e estímulos de ordem privada (CESARINO JR., 1979, v. I ). Em outras palavras, a disciplina jurídica inclui a tutela jurídica do consumo global, tutela do consumidor, suas relações com a renda global, o nível de salários, o nível de emprego, o ordenamento da repartição, o pleno emprego, as relações com o exterior, bem assim a defesa da competição.

O conceito de Constituição Econômica jurídico perpassa pelo fato de como o Direito pode conduzir o fenômeno econômico, de forma que se deve observar previamente a realidade econômica, apresentando-se a sua natureza essencialmente móvel e mutável. Ora, como afirma Tácio Gama, "o direito percebe as demandas da realidade econômica, porém sua única forma de atuar é por meio da produção de mais direito - nunca- nunca por meio da produção de realidade econômica" (GAMA, 2013, p 237). Isso quer dizer que o fato de a norma prescrever a prosperidade da nação não significa que esta o será rigorosamente, pois é o sistema econômico que deve promover a produção de riqueza e não o sistema jurídico.

Assim, deve a Constituição Econômica ser vista como um conjunto coerente de estruturas econômicas, institucionais, jurídicas e sociais organizadas a assegurar a realização da atividade econômica de uma nação. Existe a Constituição Econômica em todo o Estado, pois permite identificar as relações estabelecidas entre ela e o regime político ou a estrutura social e qual é a parte destinada respectivamente à coletividade pública, os grupos, os indivíduos (LEOLPODINO DA FONSECA, 2010, p 67/8).

A Constituição Econômica é o conjunto de preceitos e instituições jurídicas que, garantindo os elementos definidores de determinado sistema econômico, instituem uma determinada forma de organização e funcionamento da economia e constituem, por isso, uma determinada ordem econômica. Ademais, de outro modo, podem ser aquelas normas ou instituições jurídicas que, dentro de um determinado sistema e forma econômicos, que garantem e ou instauram, realizam uma determinada ordem econômica concreta (GRAU, 2015, p 78).

A Constituição Econômica opera a conversão do regime econômico em ordem jurídico-econômica. Tem esta por finalidade estabelecer os princípios e regras, informadores das normas que regerão as relações econômicas. E a regência dessas relações se dá sob dois prismas: a ordem jurídico-econômica aceita e acolhe o regime econômico existente, adotandoo como base de toda a organização que a norma implanta; a ordem jurídico-econômica procura criar um novo regime econômico. Daí o grande número de normas programáticas 
existentes nas constituições modernas, que têm por finalidade justamente reformular, dar outra forma à ordem já adotada anteriormente (LEOLPODINO DA FONSECA, 2010, p 69). Ou seja, estabelece disposições destinadas a informar a política econômica, formando uma constituição econômica diretiva.

\section{ATUAÇÃO DO ESTADO NO DOMÍNIO ECONÔMICO}

Diante da ordem econômica e da sua normatização por meio da Constituição Econômica, observa-se que a ordem jurídica apresenta aos órgãos governamentais um rol de competências para estimular, impor ou desestimular comportamentos dos agentes econômicos (BARROSO, 1998, p 32-3). Para tanto, age de forma normativa, editando normas e fiscalizando seu cumprimento. Por outro lado, age de forma participativa, atuando como agente econômico, produzindo e fazendo circular bens ou prestado serviços (GAMA, 2013, p 241).

No Brasil, observa-se a atuação participativa em diversas passagens do texto constitucional, nas quais se permite a atuação do Estado como empresário, desenvolvendo diretamente um setor da atividade econômica, havendo maior foco nos setores de segurança nacional ou para promover e atender o interesse nacional. Ou pode atuar como agente integrante das relações econômicas por meio da empresa pública, da sociedade de econômica mista e de suas subsidiárias que explorem a atividade econômica de produção ou comercialização de bens ou de prestação de serviços.

Em relação à competência para atuar de forma normativa, tem-se o Estado como regulador da atividade econômica, ditando as regras e fiscalizando o seu cumprimento para promove direitos e garantias fundamentais e direitos sociais. Esse é o caso do controle e fiscalização da concorrência para promover a defesa do consumidor, razão pela qual se passa a tecer comentários mais aprofundados sobre a atuação normativa.

Quando o Estado atua na perspectiva normativa, edita normas e fiscaliza o seu cumprimento para conduzir os negócios segundo os valores positivados na Constituição Econômica. Em outras palavras, observa-se a interferência do Estado, restringindo a liberdade econômica dos indivíduos, nos seus objetivos e instrumentos (FERRAZ JUNIOR, p 266). No entanto, a atuação normativa se subdivide em edição de normas gerais e abstratas e fiscalização do seu cumprimento, de forma que no primeiro caso há o fomento da atividade econômica e no segundo há a fiscalização da atividade econômica.

O fomento da atividade econômica possui como objetivo proporcionar meios para o desenvolvimento de algo, estimular ou desenvolver a economia. Para tanto, o Estado pode 
realizar o planejamento econômico, racionalizando a intervenção no domínio econômico (SILVA, 1994, p. 687), permitindo o desenvolvimento nacional equilibrado. Mas não só por meio de planos econômicos, mas também por promulgação de leis integradoras do texto constitucional que reprimem o abuso do poder econômico, que regulam investimentos estrangeiros e que regem o sistema financeiro nacional (BARROSO, 1998, p 41).

Em outras palavras, há a edição de normas gerais para que o Estado possa intervir, controlando e limitando os atos da autonomia privada em relação à iniciativa econômica. A edição de normas gerais que determinam condutas como obrigatórias, permitidas ou proibidas no domínio econômico sempre vem acompanhada da criação de órgãos encarregados de viabilizar o seu cumprimento. Dessa forma, surge o incentivo à atividade econômica, implementando-se os valores positivados no texto constitucional por meio da criação de órgão promotor de um determinado setor da economia (GAMA, 2013, p 252).

Por outro lado, há a fiscalização da atividade econômica através da atuação do poder de polícia estatal, nos termos do artigo78 do Código Tributário Nacional, especialmente qualificado para regular o exercício de direitos econômicos. Essa fiscalização se dá mediante o estabelecimento de normas gerais e abstratas que regulam a atividade econômica, determinando que órgãos tenham competência para disciplinar o exercício dos direitos econômicos. Dessa forma ocorre com a fiscalização da livre concorrência para fins de proteção do direito do consumidor, mediante a instituição do Conselho Administrativo de Defesa Econômica.

\section{PRINCÍPIOS DA ORDEM ECONÔMICA NO ESTADO DUALISTA}

A Constituição Federal de 1988 estabelece para o Estado estabelece as normas da tutela da concorrência, sendo assim denominada de Constituição Econômica, como visto anteriormente. A Constituição é um conjunto de normas de natureza jurídica que tem como objeto aquilo que se denomina direitos políticos, direitos civis, direitos econômicos e direitos sociais.

Em relação ao regime constitucional, observa-se o regime da democracia liberal, que dispõe sobre a livre iniciativa; e o da democracia social. Assim, deve-se aplicar as normas para ponderações dos bens, de forma que ora prevalecerá o regime liberal da economia, ora o intervencionista.

Possível também utilizar os dois regimes de forma integrativa, de forma que as normas de concorrência são interpretadas na ótica da promoção da defesa do consumidor, 
para proteger efetivamente o consumidor. A livre concorrência é uma garantia de um consumo de qualidade inserido na existência de uma vida com dignidade humana. Para garantir tais direitos, os tribunais buscam a promoção do bem estar social por causa do desenvolvimento econômico, as agências reguladoras buscam fiscalizar a promoção dos direitos individuais através da prestação de serviços, possibilidade de o Estado regular política de preços de bens e de serviços em face do poder econômico abusivo em obter lucros astronômicos.

O princípio da liberdade de empreender é o resguardo jurídico ao agente econômico de empreender o que desejar sem interferência estatal. Corresponde, na esfera econômica, à proteção jurídica dispensada ao cidadão, no âmbito político. No entanto, a liberdade é tolhida nos casos de abuso de direito de livremente empreender, justificando-se a interferência estatal em razão da liberdade de concorrência (AGUILLAR, 2006, p 227).

Em síntese, o princípio da liberdade de iniciativa é um direito do agente econômico em face do Estado, demandando uma abstenção deste, enquanto o princípio da livre concorrência é um direito do agente econômico em face de outro agente econômico, demandando não mais a omissão, mas a efetiva interferência estatal na economia (AGUILLAR, 2006, p 228).

Encontram-se dentro da liberdade de iniciativa a liberdade de comercio e indústria, a faculdade de criar e explorar uma atividade econômica a título privado, não sujeição a qualquer restrição estatal senão em virtude de lei. Cabe ressaltar que a livre iniciativa é o modo de expressão do trabalho livre numa sociedade livre e pluralista, não sendo possível identifica-la apenas concernente a uma empresa (GRAU, 2015, p 203).

O princípio da liberdade de concorrência é o contraponto do princípio da liberdade de iniciativa e não seu sinônimo. Ou seja, o agente econômico é livre para empreender, mas não pode prejudicar a liberdade de outros agentes econômicos de concorrer (AGUILLAR, 2006, p 227). Corresponde a uma situação do regime de iniciativa privada em que as empresas competem entre si, sem que nenhuma delas goze da supremacia em virtude de privilégios jurídicos, força econômica ou posse exclusiva de certos recursos, havendo a necessidade de combater aos abusos porventura decorrente da liberdade de concorrência (SANDRONI, 1999, p 118-119).

O princípio da livre concorrência afirma uma opção pelo regime de economia de mercado, garantindo-se a liberdade de concorrência como forma de alcançar o equilíbrio, não mais aquele atomístico do liberalismo tradicional, mas um equilíbrio entre os grandes grupos 
e um direito de estar no mercado também para as pequenas empresas. A Constituição Federal de 1988 adotou um aspecto positivo ao adotar como princípio a liberdade de concorrência, pois os antigos textos se preocupavam em reprimir o abuso do poder econômico (LEOLPODINO DA FONSECA, 2010, p.95).

O direito de concorrência é um elemento protetivo do direito dos consumidores e obstativo à prática do abuso do poder econômico, proibição inicialmente introduzida na Constituição de 1946 até os dias atuais (SILVA NETO, 2001, p 157).

O princípio da defesa do consumidor se torna importante quando o constituinte entendeu que um dos elos da economia de mercado é o consumidor, de forma que o Estado impõem a sua proteção tanto na esfera microeconômica e microjurídica, assim como interessa proteger o consumidor como forma de preservar e garantir a livre concorrência com a adoção de políticas econômicas adequadas (LEOLPODINO DA FONSECA, 2010, p.95). Diversos diplomas observam a proteção ao consumidor: resolução n. 39/248 de 1985 da ONU, Resoluções do Conselho de abril de 1975 e maio de 1981 das Comunidades Europeias, Constituição Portuguesa, espanhola.

Cabe ressaltar que o direito de defesa ao consumidor está como direito fundamental no artigo 5, XXXII da CF/88 e como princípio da ordem econômica. Ou seja, não pode ser modificado em caso de revisão constitucional, haja vista sua natureza de cláusula pétrea. Ademais, o direito do consumidor se compõe em direito à proteção do Estado contra a intervenção de terceiros, de modo que a qualidade de consumidor lhe atribui determinados direitos oponíveis, em regra, aos entes privados, e em menor grau ao próprio Estado (MIRAGEM, 2013, p 49). Assim, essa proteção conferida ao consumidor corresponde a um dever do Estado de promover esse direito, em face de uma relação em que há a desigualdade, Ou seja, os agentes econômicos se distinguem pelo poder econômico, conhecimento e domínio de técnica que dispõem, obtendo feixe de prerrogativas no âmbito negocial em face do consumidor, que se encontrar em posição de fragilidade e vulnerabilidade (MIRAGEM, 2013, p 51).

A proteção do consumidor visa salvaguardar um bem jurídico do consumidor individual quanto pela coletividade de consumidores ou até mesmo de uma pessoa jurídica como consumidora, haja vista que esta pode se encontrar em posição de subordinação estrutural em relação ao produtor do bem, produto ou serviço. A Constituição Federal de 1988 assim reconhece a necessidade de sua proteção ao indicar nos artigos 5, XXXII como direito fundamental, $150, \S 5^{\circ}$, a necessidade de esclarecimento dos consumidores quanto aos 
impostos que incidem sobre mercadorias e serviços e artigo 48 da ADCT que determina a promulgação do Código de Defesa do Consumidor, além do inciso V do artigo 170 que estabelece como princípio conformador da ordem econômica.

Quando presente como princípio da ordem econômica, a defesa do consumidor se apresenta com um conteúdo interventivo e promocional, de efetivação dos preceitos constitucionais que o estabelecem como direito e como princípio. Assim, tem-se um caráter conformador da ordem econômica. Cabe ressaltar que não há distinção de importância ou hierarquia maior ou menor em relação a qualquer princípio da ordem econômica. Em outras palavras, em caso de colisão entre eles, deverá ser realizado um juízo de proporcionalidade, buscando dar maior efetividade ao princípio conformador do Estado Democrático de Direito: dignidade da pessoa humana. Dessa forma, insere-se o conteúdo próprio do direito fundamental de defesa do consumidor, que acabará por determinar em caso de aparente colisão de princípios, opção por qual deles tutelará de mais efetivo a realização das necessidades da pessoa humana.

Diante da análise dos princípios norteadores, tem-se que, no Estado dualista cabe a ideia de conciliação dos princípios da livre iniciativa e da livre concorrência como meio de realizar a justiça social, porque o Estado é ao mesmo tempo impulsionador e partícipe da atividade empresarial, árbitro da distribuição e senhor da organização dos mercados, mas também impõem eficiência e redistribuição para realizar o bem-estar (VIGIDAL, 1973, p 156157).

Embora já existissem legislações infraconstitucionais que tratavam da proteção da livre concorrência, observa-se que o direito da concorrência e do consumidor aportam nas constituições ainda antes da segunda grande guerra, com vistas a assegurar o bem-estar do homem. Ou seja, no último estágio da evolução das constituições, observa-se a linha de um Estado dualista do bem-estar social e do desenvolvimento econômico, surgido da dialética entre a tese da plena liberdade de inciativa e a antítese do Estado único empresário (BRITO, 2016, p 213). Assiste-se, assim, o nascimento do Estado intervencionista que busca o desenvolvimento econômico para poder realizar o bem-estar social. Ocorrem reflexos jurídicos em razão dessa atuação estatal no domínio econômico, podendo-se citar as transformações nas estruturas política e econômica da sociedade, por duas tendências: a primeira, a de o Estado apossar-se do indivíduo e tomando-lhe a posição de protagonista indiscutível; a segunda, a de dirigir a sociedade passando modelá-la como um tutor. No 
aspecto das normas jurídicas, surgiram-se os conceitos de boa-fé objetiva, a de causa, o dirigismo contratual e a teoria do abuso do direito.

Além disso, o direito de concorrência é o centro de preocupação hoje para garantir a proteção ao consumidor. Se há o direito e o dever de concorrer, estará assegurado o direito à livre iniciativa. Está assegurado o direito de ingressar no mercado e garantida a sua permanência. Se se garante a livre concorrência, impõe-se aos concorrentes o deve de ofertar sempre o pelo melhor preço, pela melhor a qualidade. Com a garantia da livre concorrência protege-se o consumidor, a quem se garante o direito da livre escolha. Protege-se também o trabalhador, pois que estarão integrando o mercado de empresas que lhe propiciam maior oportunidade de trabalho, com perspectiva de melhores salários (LEOLPODINO DA FONSECA, 2010, p.320).

\section{CONTROLE DO MERCADO COMO DEFESA DO CONSUMIDOR}

\subsection{HISTÓRICO DO CONTROLE DA ECONOMIA}

O Estado pode ter um planejamento da economia, isto é, organização econômica na linha de um intervencionismo oficial, o qual somente é compatível com a dignidade da pessoa humana, se for moderado, porque a sua função é assegurar a competição para beneficiar o consumidor, impedindo o abuso do poder econômico que resulta, também, do ato de concentração.

A primeira lei anti-truste foi o ACT for the prevetion and Supression of combinatons formed in Restraint of Trade, de 1889, do Canadá, proveniente de uma política protecionista que levou ao fracasso da economia canadense na tentativa de modificar a situação econômica do país. Em 1890, a Lei norte-americana antitruste - Scherman Act - teve como objetivo a proteção do comércio interestadual contra as restrições da concorrência e foi o impedimento para que se formassem os monopólios.

Em 1911, a Suprema Corte, no caso Stantard oil Co. v United States, introduziu a chamada rule of reason, ou regra da razoabilidade, com vistas a abrandar a interpretação estrita decorrente da ilicitude do truste, de forma que condutas que limitavam a concorrência poderiam ser aceitas desde que trouxessem melhorias e eficiência.

A maioria dos países se protegem dessas práticas ilícitas de domínio do mercado. Esta preocupação se demonstra em âmbito internacional com a Resolução n; 39/248 da ONU de 1985. 
O Brasil sempre apresentou leis contra os crimes contra a economia popular, repressão ao abuso do poder econômico.

A Constituição de 1824 e a de 1891 não trataram da intervenção do estado no domínio econômico. A Constituição de 1934, por sua vez, já determinava a intervenção dentro dos limites da justiça e do atendimento das necessidades da vida nacional, de modo a possibilitar a todos a existência digna, liberdade econômica sendo garantida. Em outras palavras, sob a influência das constituições do México, da URSS e de Weimar, tratou da organização da economia, trazendo os primeiros aspectos do conceito de constituição econômica.

Em 1937, a Constituição passou a tratar da intervenção do Estado de forma direta, para suprir as deficiências da iniciativa privada, e a indireta, evitando que o jogo das competições individuais excluísse o pensamento dos interesses da Nação, como a economia popular.

Outras leis apareceram, como a Lei federal $n^{\circ}$ 8.884/94, a Lei 12.529/2011 os Termos de Compromisso de Cessação, regulamentados pelo Conselho Administrativo de Defesa Econômica.

\subsection{FUNDAMENTOS DO CONTROLE DE MERCADO E INSTRUMENTOS NORMATIVOS}

Controlar o mercado é salutar na medida em que se tenha como objetivo manter sadia concorrência entre os seus agentes, impedindo a concentração ilícita. Contudo, essa operação não é um fim em si mesma. O seu fundamento é, efetivamente, o consumidor, titular de um direito subjetivo de defesa que se finca no princípio do bem-estar social. Não é à toa que a Constituição é fonte imediata do direito subjetivo público de defesa do consumidor, outorgando competência concorrente para os entes federados legislarem sobre o consumo e sobre a responsabilidade por dano ao consumidor, ter determinado prazo para a edição de uma lei específica, como é o Código de Defesa do Consumidor, também erigindo-se em nível de princípios da organização da economia a defesa do consumidor imbricada com a livre concorrência.

Assim, o fundamento maior do controle do mercado é a defesa do consumidor que se reflete nas diversas transformações nas estruturas políticas e econômica da sociedade. A ordem jurídica brasileira restaura os princípios da ordem social, o do equilíbrio contratual com vistas a corrigir desproporção entre as partes e a situação de vulnerabilidade. O equilíbrio 
contratual atina, de um lado, com uma orientação de direitos e deveres e, de outro, com o problema do equilíbrio econômico. O desiquilíbrio dos direitos e deveres se esbarra na ideia de boa fé, havendo soluções para tanto: cláusula "rebus sic santibus", inversão do ônus da prova nos casos de hipossuficiência e vulnerabilidade, anulabilidade em caso de vícios contratuais referentes à vontade, nulidade de pleno direito das cláusulas contratuais que estabeleçam nos contratos civis taxas de juros superiores às legalmente permitidas, assim como lucros e vantagens patrimoniais excessivos, estipulados em situação de vulnerabilidade da parte nos negócios não disciplinados pelas legislação comercial e de defesa do consumidor.

O ordenamento jurídico brasileiro tem-se preparado em função da nova tutela estatal surgida com a proteção dos interesses socais indisponíveis, dos interesses difusos, criando não somente normas de direito material, mas também outras disciplinadoras da aplicação desse direito substantivo como verdadeiras garantias a serem reivindicadas perante órgãos de sua estrutura administrativa e judicial (BRITO, 2016, p 226).

Numa sociedade de massas na qual o consumo caracteriza relações inassimiláveis pelo individualismo jurídico, o intervencionismo estatal se impõe para um planejamento da economia, isto é, para a organização econômica na perspectiva de uma interferência oficial moderada, cuja função é assegurar a competição para beneficiar o consumidor, impedindo o abuso do poder econômico. A Constituição Federal do Brasil de 1988 determina que a organização da economia tenha como objetivo assegurar a todos uma existência digna, conforme os ditames do bem estar social, vinculando-se três princípios como núcleo a ser observado para tanto: função social da propriedade, livre concorrência e defesa do consumidor. Assim, o Estado pode regular o mercado com medidas oficiais- legislativa ou administrativa, não restringindo o exercício de direitos outorgados pela própria CF (BRITO, 2016, p 227).

Para Miguel Reale Junior, há de conseguinte, ao lado do dano sofrido pelo empresário, em razão de uma prática concorrencial desonesta, um prejuízo para os consumidores. Se há um dano para o empresário cujo concorrente agiu deslealmente, não deixa de haver lesão ao interesse difuso dos consumidores. Pode ser irrisório o interesse de cada qual dos compradores, mas é de relevo o prejuízo quanto vislumbrado o desrespeito à honestidade que frauda e ludibria a massa dos consumidores, que escolhem o pressuposto de uma verdade de informação. Tendo a propriedade função social, não pode a massa consumidora ser enganada, pois seria supervalorizar a livre iniciativa, sobrepondo-se ao interesse geral. Por tais razões, tanto se ressalta hodiernamente que a ilicitude ou incriminação 
da concorrência desleal visam proteger o interesse geral, o interesse dos consumidores (REALE JUNIOR, 1983).

É indiscutível que a dominação de mercados, a imposição de preços e o aumento arbitrário de lucros prejudicam a vida do consumidor, de sorte que a firme repressão e essas condutas redundará em benefício para o consumidor. É a defesa da ordem econômica depurando o mercado e, indiretamente, melhorando a situação do consumidor (ALMEIDA, 2009, p 318).

Para o Supremo Tribunal Federal, quem atua no domínio econômico tem a livre iniciativa, mas esta é limitada pelo bem-estar social. Ou seja, não há atuação livre no âmbito econômico, de forma que o poder econômico exercido pelos entes privados sempre objeto do controle oficial para evitar seu exercício abusivo (BRITO, 2016, p 228).

Além dessas situações, cabe observar que houve uma evolução dos direitos individuais absolutos, conduzindo ao surgimento da função social da propriedade, dos contratos, limitando-se direitos, liberdades típicas das relações privada. Dessa forma, permitese que o Estado possa intervir para garantir a igualdade material, limitando a liberdade de alguns para garantir a solidariedade no mercado e assegurar direitos imperativos aos mais fracos (BENJAMIN, 2014, p 44/46).

Com vistas a efetivar a intervenção, o Estado vem editando leis para proteger o consumidor, interferindo na economia. É o caso do Código de Defesa do Consumidor, legislação que cuida da repressão ao abuso econômico e demais legislações que tratam de matéria correlata (ALMEIDA, 2009, p. 27).

Um exemplo recente de instrumento normativo é a lei no Lei 13.455/2017 que permite aos comerciantes cobrarem preços diferentes para um mesmo produto, dependendo da forma como o cliente paga e do prazo de pagamento. Assim, o comerciante fica autorizado a cobrar um preço de quem paga com cartão e outro de quem paga em dinheiro, por exemplo. A prática, apesar de já ser comum no comércio, era proibida. A mudança foi proposta em dezembro pelo governo em forma de uma medida provisória. Como MPs têm validade imediata, a regra já estava em vigor desde aquela época. O texto, porém, teve que passar pelo Congresso, onde foi aprovado e enviado para sanção ou veto presidencial. A sanção foi realizada no mesmo ano, em 26 de junho de 2017.

Não só as leis, mas também há órgãos que buscam fiscalizar a livre iniciativa, protegendo o consumidor, como os chamados PROCON's, os contenciosos administrativos, os conselhos nacionais de defesa do consumidor e da concorrência, os juizados especiais e os setores especiais do Ministério Público com titularidade para as ações civil e penal pública. 
Além da presença de normas que protegem o consumidor, há legislação cuja matéria atina com a repressão de abusos nas práticas econômicas, além de se observar a inserção dos agentes econômicos nas relações de consumo de uma sociedade em que os contratos são celebrados em massa (BRITO, 2016, p 204). As referidas normas são instrumento de realização das aspirações sociais no Estado dualista do desenvolvimento e do bem-estar social, devendo o intérprete buscar o objeto econômico da norma de concorrência, porque imbricada com as relações de consumo, estando o resto do relato pertinente com a fórmula constitucional quanto à competência (União, Estados, DF ou Municípios).

As normas que tratam da concorrência possuem sanção, que se encontra na seara penal, sendo de competência da União, ou administrativa, sendo, neste caso, de competência de qualquer dos outros entes políticos para legislar

Somente os bens que integram a ordem pública em geral, quando ofendidos por ilicitude econômica importam ao direito penal, ou seja, quando o fato agride valores da comunidade em razão de uma conduta humana(BRITO, 2016, p 209). O legislador, no entanto, não pode desobedecer aos seguintes princípios para caracterizar o tipo criminal ou aplicabilidade da sanção: razoabilidade da lei, proporcionalidade da sanção, extinção de punibilidade, insignificância da infração, oportunidade, subsidiariedade do direito penal, direito penal da culpa.

Cabe observar que a tutela da concorrência, no sistema do direito positivo brasileiro é matéria de direito econômico e não de direito penal, considerando que o fato de reprimir práticas econômicas abusivas não caracteriza essa tutela como própria do direito penal, que é a forma de punição a quem comete uma falta no campo em que se permite identificar a culpa elemento caracterizador do elemento subjetivos de consciência do justo e do injusto (BRITO, 2016, p 211). O interesse econômico nem sempre coincide com o dos particulares e se se entender a expressão interesse econômico como sinônima de proveito pecuniário, somente se legitimará a criminalização do ilícito econômico quando o interesse econômico estatal estiver diretamente relacionado com os interesses da coletividade e, portanto, num plano superior àqueles próprios da economia privada (SANTOS, 1981, p 104).

\subsection{DEFESA DA LIBERDADE DE CONCORRENCIA COMO DEFESA DO CONSUMIDOR}

A busca do fortalecimento de uma indústria nacional tende a conduzir a um privilegiamento da concentração, sendo considerada esta em tempos primórdios como 
sintoma da saúde do sistema econômico. No Brasil, de fato, o Direito Concorrencial somente veio a se fortalecer com a mudança do perfil regulatório, na década de 1990, que passou a privilegiar a competição como instrumento de controle de preços e de qualidade de bens e serviços

O Brasil se inspirou no modelo norte-americano no que tange à dicotomia de ação administrativa e ação judicial, a partir da existência de entidades com funções específicas e distintas: Antitrust Division e a Federal Trade Commission. A primeira é uma agência reguladora a quem compete o combate à concentração ilícita, promovendo, junto ao judiciário, a aplicação de sanções cabíveis. É sua função a de fazer cumprir as leis antitruste. A segunda é uma agência administrativa com competência mais ampla no combate ao abuso do poder econômico, sobretudo com atuação preventiva da formação ou mesmo da ampliação de atividades empresariais que possam assumir caracteres monopolísticos. Promove a defesa do consumidor e a eliminação e prevenção de práticas negociais monopolísticas ou anticompetitivas. Assim, é uma comissão de comércio federal com poderes regulamentares, representando uma alternativa para a lentidão dos tribunais, diante da velocidade da atuação negocial que, por isso, necessita ser vigiada, permanentemente, em tempo real, para evitar que resvale para circunstâncias irregulares de operação de mercado (BRITO, 2016, p 229).

O Brasil previu a Comissão Administrativa de Defesa Econômica, através do Decreto-lei $\mathrm{n}^{\circ} 7.666 / 45$, com atribuições típicas de uma agência reguladora, tal como essas comissões norte americanas foram instituídas. O Conselho Administrativo de Defesa Econômica - CADE nasceu dessa inspiração da Comissão, sendo criado pela Lei Federal $n^{\circ}$ 4.137/92, com a competência para apurar e reprimir os abusos do poder econômico, dando execução à lei.

O CADE já foi considerado um órgão sui generis, nas palavras de Nestor Duarte, por não se comportar ou se prender ao quadro de simples repartição pública ligada e presa ao que se chama administração direta. Quanto à ida ao juízo, através do seu procurador, não haveria estranheza porque os procuradores da República não estão sempre em juízo em nome da União, mas do Estado (BRITO, 2016, p 230). Atualmente, prevalece o entendimento de que é uma autarquia federal, nos termos do artigo $3^{\circ}$, da Lei 8.884/94, repetido pela Lei 12.529/2011, sendo uma espécie de tribunal administrativo com funções quase-judiciais, vinculado ao Ministério da Justiça. Ademais, possui competência para deliberar sobre a existência da infração à ordem econômica, aplicando as penalidades previstas em lei, assim 
como pode requerer ao judiciário a execução de suas decisões, até porque sua atribuição é para aplicação de sanções às infrações da ordem econômica independentemente de culpa.

Atua combatendo o exercício abusivo do poder econômico, sendo este considerado a eliminação da concorrência e aumento arbitrário dos lucros. O abuso do poder econômico consiste numa infração à ordem econômica, mas é apenas mais uma das hipóteses de ato anticoncorrencial ilícito, posto que não se deve mais apreciar apenas se os atos anticoncorrenciais são praticados mediante abuso de poder econômico (AGUILLAR, 2006, p 234).

O poder econômico se demonstra quando ele se manifesta por uma força de capital que venha ser confrontante com todas as outras forças vivas ou de poder que existem na sociedade, especialmente quando esse confronto se faz com o poder chamado de formal, ou seja, o poder político, o poder de dominação, propriamente dito (BRITO, 2016, p 239). Em razão disso, tem-se que a Constituição Federal de 1988 trata da matéria do poder econômico de maneira relativa porque ela própria não tem uma noção do que é poder econômico para a orientação jurídica, embora estabeleça aspectos do que seria abuso do poder econômico. Assim, permite-se construir um conceito: quando a atividade econômica representar uma dominação dos mercados aí existe um poder econômico e ele está sendo exercido de modo abusivo.

Ocorre que há relatividade também quanto aos objetivos do exercício abusivo do poder econômico, ou seja, não se tem um conceito de dominância de mercado, de eliminação da concorrência ou de aumento arbitrário dos lucros. Deve-se observar as circunstâncias do caso concreto, de forma que somente o poder judiciário pode construir o que é que representam esses três elementos que compõem a noção de poder econômico e do exercício abusivo desse poder (BRITO, 2016, p 240).

A fim de se identificar o conceito de concentração como exercício abusivo do poder econômico, busca-se caracterizar as formas diretas e indiretas de concentração mediante a análise das operações de mercado. As formas diretas de concentração são o cartel, o monopólio, o oligopólio, o monopsônio e oligopsônio. As indiretas são técnicas ainda não tipificadas, mas que buscam identificar as concentrações horizontais ou verticais, não definidas anteriormente.

As práticas restritivas horizontais consistem na tentativa de reduzir ou eliminar a concorrência no mercado, seja estabelecendo acordos entre concorrentes no mesmo mercado relevante com respeito a preços ou outras condições, seja praticando preços predatórios, 
visando o aumento de poder de mercado ou à criação de condições necessárias para exercê-lo com maior facilidade: cartéis, outros acordos entre empresas, ilícitos de associações profissionais e preços predatórios (AGUILLAR, 2006, p 236/7). As práticas restritivas verticais, por sua vez, são aquelas impostas por produtores ou ofertantes de bens ou serviços em determinado mercado sobre mercados relacionados verticalmente ao longo da cadeia produtiva. Em casos de restrições verticais, deve-se proceder a uma análise da interação entre diferentes mercados relevantes. Tais práticas pressupõem a detenção e poder econômico capazes de influenciar tanto o mercado de origem quanto o mercado-alvo, configurando risco de prejuízo à concorrência.

Malgrado esta análise, se as restrições propiciarem eficiências econômicas, de acordo com o princípio da razoabilidade, estas devem ser ponderadas em relação aos efeitos potenciais anticompetitivos. A eficiência econômica consiste em cobrar menos de consumidores de volumes maiores de serviços públicos, em função de economias de escalas (AGUILLAR, 2006, p 238).

$\mathrm{O}$ ato de concentração também se vislumbra como uma forma de abuso do poder econômico. Este tem uma interface com a concorrência, por isso ele pode ser lícito, quando não a ofende, e ilícito, quando a dificulta ou a elimina. Quando há a eliminação da concorrência, ofende-se a proteção do consumidor, pois fica à mercê de preços abusivos e de bens para a sua subsistência, abaixo do padrão de qualidade. Se houver a concorrência, instaura-se a possibilidade de escolha desses bens, apurando-se sobre quais são os melhores.

A concentração é boa para diminuir custos, haja vista que racionaliza a atividade econômica, eliminando-se a concorrência, reunindo-se todas as etapas do processo produtivo, centralizando-se as condições de fixação de preços sem o temor da competição, prejudicandose o consumidor, no entanto. Por isso, a concentração empresarial é controlada para que não haja condutas anticoncorrenciais, sendo a competitividade zelada pelo Sistema Brasileiro de Defesa da Concorrência, a Secretaria de Direito econômico e a Secretaria de Acompanhamento Econômico e o CADE. O referido controle é exercido sobre atos de fusão ou incorporação de empresas ou qualquer outra forma de agrupamento societário, que implique participação de empresa ou grupo de empresas resultante em $20 \%$ de um mercado relevante, ou em que qualquer dos participantes tenha registrado faturamento bruto anual no último balanço equivalente a quatrocentos milhões de reais.

Assim, os atos que possam limitar ou prejudicar a livre concorrência, ou resultar na dominação de mercados relevantes de bens ou serviços, devem ser submetidos à apreciação 
do CADE, principalmente os atos de concentração economia. Dessa forma, o CADE analisará se $\mathrm{o}$ ato aumenta a produtividade, melhora a qualidade de bens ou serviços ou propicia a eficiência e o desenvolvimento tecnológico ou econômico, se os benefícios são distribuídos entre os empresários envolvidos e os consumidores, não pode implicar eliminação da concorrência da parte substancial de mercado relevante de bens e serviços, assim como o ato deve observar os limites necessários para tingir os objetivos visados. Se o ato for necessário à economia nacional e ao bem comum e não importar em prejuízo aos consumidores, poderá o CADE admitir que apenas três dos quatro requisitos sejam satisfeitos. A vagueza e imprecisão desses termos têm facilitado a justificativa para que qualquer ato de concentração seja aprovado.

A legislação brasileira, portanto, se pauta na identificação da conduta abusiva pela análise do objetivo do agente e pelos efeitos do ato praticado, seguindo as influências do sistema norte americano, buscando-se uma interpretação vinculada à razoabilidade. Ocorre que a Constituição Federal de 1988 apenas indica como abusiva a identificação da finalidade do ato do agente, enquanto a legislação infraconstitucional considera dois vetores, aumentando a repressão: cabe reprimir os atos com efeitos e/ou realizados com a finalidade de diminuir a concorrência. No entanto, o simples fato de a norma constitucional não ter mencionado outros casos suscetíveis de repressão, não significa que outras situações não possam estar previstas a lei ordinária, haja vista que estabelece o texto constitucional a liberdade de concorrência à condição de princípio da ordem econômica constitucional e proteção ao consumidor, desde que preservado o princípio da liberdade de iniciativa (AGUILLAR, 2006, p 230).

\subsection{AGÊNCIAS REGULADORAS, SERVIÇOS PÚBLICOS E A CONCORRÊNCIA}

Os serviços públicos eram tradicionalmente desempenhados em regime monopolístico pelo Estado, de modo que não havia a mais remota possibilidade de se falar de regulação pela concorrência. Cabe ressaltar que, atualmente, a concepção de serviço público abrange a atividade do Estado destinada ao atendimento de necessidades vitais para a população, podendo os particulares prestarem tal serviço sob a orientação e fiscalização do Estado (BRITO, 2016, p 32).

Com a saída de cena do Estado da operação de serviços públicos monopolisticamente, exige-se que ele regule a atividade dos prestadores privados de serviços públicos, porque a Constituição Federal de 1988 não faculta ao Estado decidir se serviços 
públicos são ou não de sua alçada. Se não quiser fazer diretamente, poderá delegar a particular, desde que faça por licitação e mediante regime de concessão ou permissão. Assim, caberá ao Estado se dedicar a regular a atividade delegada, surgindo, então, as agências reguladoras (AGUILLAR, 2006, p 244).

A criação das agências reguladoras tem a ver com a autorização, concessão ou permissão de prestação de serviços públicos por empresas privadas. Mas essas mesmas empresas passarão a concorrer no mercado, com a finalidade de prestar ao consumidor um serviço mais eficiente, de menor custo, de melhor qualidade, de menor preço. A concorrência no mercado sujeitará essas empresas à competência fiscalizadora dos órgãos legalmente criados e habilitados para essa função, como é o caso da ANATEL.

A atividade de controle da concorrência em relação aos serviços públicos é peculiar, haja vista que há a licitação para acessar ao mercado, assim como a concorrência se dá apenas entre os prestadores de serviços habilitados para tanto. A licitação atua como mecanismo regulatório, criando uma concorrência institucional, destinada a simular uma situação de competitividade de mercado antes de ser fixado o valor das tarifas. E esse valor será ajustado de acordo os critérios identificados na licitação.

Assim, o Estado delimita o espaço da competição entre prestadores, limitando o mercado, seus integrantes, a quantidades de participantes, o espaço territorial e a variedade de concorrentes. Além disso, determina a tarifa a remunerar os serviços, vencendo o licitante que oferecer o melhor preço à administração pública. Não haveria que se falar em prática abusiva de preços em decorrência de regime de restrição de concorrência. Dessa forma, acaba por direcionar e estimular a dispersão ou a concentração empresarial no setor.

Além disso, há além do controle estrutural, destinado aos atos de concentração, e do controle de condutas, destinado a combater práticas anticoncorrenciais, com caráter repressivo, há o marco regulatório dos serviços públicos realizado pelos entes que concede o serviço público.

Em terceiro lugar, observa-se a infraestrutura. Os serviços públicos prestados em rede dependem de uma infraestrutura física e logística complexa custosa e dificilmente duplicável. Essa circunstância tem impacto direto sobre a liberdade de concorrência, pois o detentor da rede física tende a constituir um monopólio natural, excluindo os demais concorrentes do mercado. Somente pode haver um regime de competição livre na exploração de serviços públicos estruturados em rede, na medida em que o acesso a essa infraestrutura seja assegurado pelo Estado, por meio de mecanismos de controle jurídico da gestão da 
infraestrutura. Dessa forma, a análise da concentração requer uma consideração desse particular mercadológico, havendo uma certa alteração no procedimento de controle de concentrações realizados pelos órgãos de defesa da concorrência.

Por fim, há uma profunda transformação do regime jurídico da prestação dos serviços públicos, na medida em que se introduz a técnica de regulação pela concorrência, que exige a presença do Estado e não sua omissão.

A questão, em verdade, segundo Aguillar, é dado o poder enorme de que dispõe a agência reguladora, na construção do mercado de serviços públicos, é importante que suas decisões tenham lastro em critérios democráticos, porque há um risco muito elevado de que decisões tão difíceis quanto impactantes sejam adotadas ao sabor de conveniências das mais variadas espécies, mas que nem sempre coincidem com as dos usuários dos serviços públicos (consumidores) (AGUILLAR, 2006, p 246/7).

\section{CONSIDERAÇÕES FINAIS}

Em razão da alteração da estrutura do Estado liberal para o Estado social dualista do bem-estar social e do desenvolvimento econômico, tipicamente intervencionista e adepto integral do dirigismo econômico, observam-se os reflexos jurídicos da atuação do estado no domínio econômico. Essa atuação é primordial para promover os direitos elencados na Constituição Federal de 1988, integrando-os na perspectiva de elevar o desenvolvimento econômico do país.

O Estado atua como um agente tanto normativo, como persuasivo e/ou participativo, de forma que regulariza a atividade econômica, fiscaliza-a e a controla, assim como realiza atividade econômica como se empresário fosse nos casos das empresas públicas e sociedades de econômica mista. No entanto, a intervenção na economia deve respeitar a constituição econômica constituída de valores sociais e de direitos da livre iniciativa. Mas não só dos que exercem a atividade econômica, os direitos dos consumeristas também devem ser promovidos e protegidos, sob pena de se voltar à época de um Estado minimalista e abstencionista em relação aos direitos dos vulneráveis.

Cabe ressaltar que três princípios são relevantes para a análise da temática abordada no presente artigo: a liberdade de iniciativa, a livre concorrência e os direitos dos consumidores. Relacionam-se na medida em que justificam a atuação do Estado quanto ao controle da concorrência para evitar o abuso do poder econômico e prejuízo aos cidadãos. Ao proteger a livre iniciativa, promove o Estado o desenvolvimento da economia do país, com 
facilidades institucionais para os pequenos empresários, incentivo às atividades econômicas. Ademais, com o controle da concorrência, evita-se que o exercício da atividade econômica do país seja limitado aos grandes grupos, impedindo que atividades outras sejam desenvolvidas. No que pertine à defesa da livre concorrência, esta se dá com o intuito de impedir a concentração empresarial e o abuso o poder econômico num mercado, para que os consumidores e demais empresários não sejam lesados quanto aos seus direitos constitucionalmente garantidos.

Assim, com o fim de promover os direitos consumeristas, a administração pública realiza a intervenção mediante coação, estímulo ou persuasão e prestação, ainda que supletiva. No caso do controle da livre concorrência, observam-se as leis que identificam as condutas abusivas e contrárias aos valores da ordem econômica prevista na Constituição Federal de 1988. Ademais, há instituição de órgãos de controle da livre iniciativa, como é o caso do Conselho Administrativo de Defesa Econômica - CADE, bem como de fiscalização da atividade empresária atinente à prestação de serviços públicos por meio de concessão ou permissão, diante das agências reguladoras.

Nesse contexto, evidencia-se o controle do mercado para evitar a concentração danosa aos interesses do consumidor, entendendo-se, por isso, a livre concorrência como um direito subjetivo do consumidor.

\section{REFERÊNCIAS}

AGUILLAR, Fernando Herren. Direito Econômico: do direito nacional ao direito supranacional. São Paulo: Atlas, 2006.

ALMEIDA, João Batista de. A proteção jurídica do consumidor. $7^{\mathrm{a}}$ ed. Ver. E atual. São Paulo: Saraiva, 2009.

BARROSO, Luis Roberto. Crise econômica e direito constitucional. Revista Trimestral de Direito Público, São Paulo: RT, v. 6, 1998.

BENJAMIN, Antonio Herman V, MARQUES, Claudia Lima, BESSA, Leonardo Roscoe. Manual de direito do consumidor. $6^{\mathrm{a}}$ ed. ver.e ampl.São Paulo: Editora Revista dos Tribunais, 2014

BRITO, Edvaldo. Reflexos jurídicos da atuação do Estado no domínio econômico. $2^{\mathrm{a}}$ ed. São Paulo: Saraiva, 2016

CARVALHO, Kildare Gonçalves. Direito Constitucional - Teoria do Estado e da Constituição - Direito Constitucional Positivo - 17 edição, DelRey Editora, 2011 
Ciência do Direito Constitucional, Ciencias Constitucionais e Afins. Disponível em: <http://mundodedireito.blogspot.com.br/2011/03/ciencia-do-direito-constitucional.html>. Acesso em 03 jul 2017.

CESARINO JR., A. F. Direito social brasileiro. São Paulo: Saraiva, 1979, v. I.

COMPARATO, Fabio Konder. Ordem econômica na constituição brasileira de 1988. Revista de Direito Público, Rio de Janeiro: Forense, 1999.

FERRAZ JUNIOR, Tércio Sampaio. Fundamentos e limites constitucionais da intervenção do Estado no domínio econômico. Revista de Direito Público. São Paulo: RT, n. 47-48.

FRANCESCHINI, José Inácio Gonzaga. Introdução ao Direito da Concorrência. São Paulo: Malheiros, 1996

GAMA, Tácio Lacerda. Contribuição de intervenção no domínio econômico. São Paulo: Quartier Latin, 2013.

GRAU, Eros Roberto. A ordem econômica a constituição de 1988. Interpretação e crítica. $17^{a}$ ed. atual. São Paulo: Malheiros,2015

LEOLPODINO DA FONSECA, João Bosco. Direito econômico. Rio de Janeiro: Forense, 2010.

MAGANO, Octávio, Bueno. Introdução ao direito econômico. São Paulo: Editora Juriscrédi Ltd., [s.d.].

MIRAGEM, Bruno. Curso de direito do consumidor. $4^{\mathrm{a}}$ ed. São Paulo: Editora Revista dos Tribunais, 2013.

REALE JUNIOR, Miguel. Concorrência desleal e interesse difuso no direito brasileiro. Revista de Direito Mercantil. 49: 5-13, jan/mar, 1983, ano 22.

SANDRONI, Paulo. Novíssimo dicionário de economia. São Paulo: Editora Best Seller, $2^{\mathrm{a}}$ ed., 1999.

SANTOS, Gérson Pereira dos. Direito Penal econômico. São Paulo: Saraiva, 1981.

SILVA, José Afonso da. Curso de direito constitucional positivo. $9^{a}$ ed. São Paulo: Malheiros, 1994.

SILVA NETO, Manoel Jorge e. Direito constitucional econômico. São Paulo: LTr, 2001.

VENANCIO FILHO, Alberto. A intervenção do estado no domínio econômico: o direito público econômico no Brasil. Rio de Janeiro: Renovar, 1998.

VIGIDAL, Geraldo. Fundamentos do direito financeiro. São Paulo: Revista dos Tribunais, 1973.

Revista de Direito, Economia e Desenvolvimento Sustentável | e-ISSN: 2526-0057 | Salvador | v. 4 | n. 1 | p. 